\title{
The characteristics and statistical parameters of the exhibition building fire load
}

\author{
Jinping Wang \\ China Academy of Building Research, Beijing 100013, China \\ wangjinping@126.com
}

Keywords: fire load; exhibition building; investigation; fire design

\begin{abstract}
Carried out fire load survey of exhibition building in Beijing, and obtained a lot of data. On preliminary theoretical studies results the data has been analyzed, and then determined the fire load density standard value $876.21 \mathrm{MJ} / \mathrm{m}^{2}$, average of $382.97 \mathrm{MJ} / \mathrm{m}^{2}$. The data is not refused to obey the extreme value I distribution type. In the fire protection design simulation the standard value is suggested to be used.
\end{abstract}

\section{Introduction}

The general exhibition is used as temporary exhibit public buildings, the flow of people is great and exhibition is complex and diverse, and there are many different types of exhibitions such as industry, agriculture, trade, transportation, science and technology, arts and culture. With the rapid economic development, the large exhibition building is more and more, the large-scale exhibition hall has big construction scale, personnel-intensive, the complex use function, and there is many combustible material to form fire hazards.

\section{The fitment status}

Fixed decoration of the general exhibition building would tend to be simplified, the large space didn't split. During the exhibition, according to the exhibition nature the exhibit hall will be re-decorated. The normal combustible material conclude as the standard booth of exhibition in general include one office unit, desk, chair, clapboard (made of fiber hardboard), computer, publicity paper and exhibition products, etc..

\section{Fire characteristics}

The fire district of the large exhibition hall can not meet the use of functional requirements. There often exist not standardized electricity, pull privately wires, sockets, etc. and the human is more focused in the hall during the exhibit period, and generally not familiar with the hall, evacuation routes, fire fighting equipment, emergency measures. If there is fire, the smoke danger is seriously and the evacuation is very difficult.

\section{Results of exhibition hall Fire load survey}

\section{Fire load survey of exhibition}

One Beijing exhibition building was chosen to go along the fire load survey. It is Beijing's first large-scale, comprehensive exhibition hall, and has been built more than 40 years, the exhibition building has received more than 1,000 domestic and foreign large-scale exhibition and the number of billion times. The exhibition covers various fields of international economic, trade, science and technology, culture and politics, and military. This is also the exhibition building actually status.

During the investigation in the exhibition hall, it is ongoing Tour exhibition. some participating countries and regions used wood, straw and other materials to realize their own creativity, to express the charm of their region; some exhibitors only display in a office suite, with a desk and chair to put out publicize materials, the exhibition in this way is the most common. We include all this regional 
scope in the investigation, so that the survey data is more representative, on this basis, we have as much as possibly selected more combustible materials points in order to the fire risk in the greatest degree to be controlled [1-3].

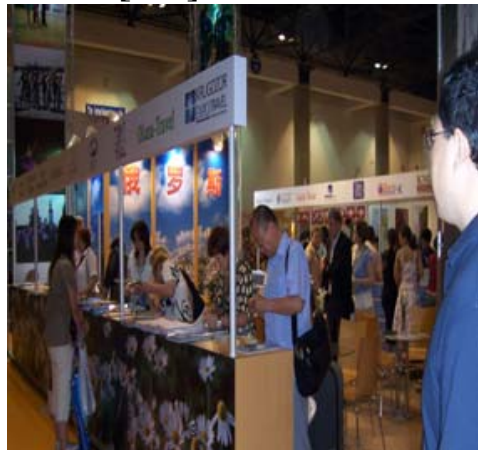

Fig. 1 Survey photo

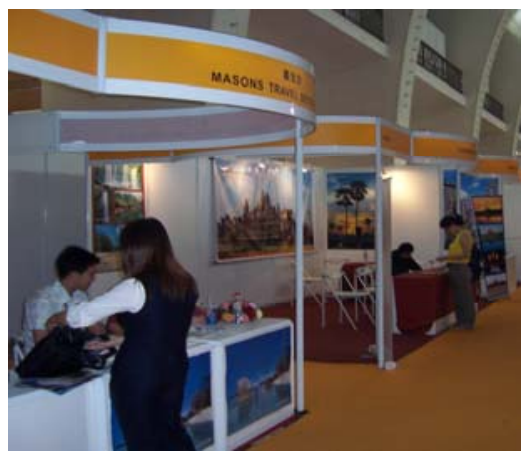

Fig. 2 Survey photo

\section{The histogram and the statistical parameters}

Through the exhibition survey we obtained a total of 56 valid data, the fire load density from 96.92 $\mathrm{MJ} / \mathrm{m}^{2}$ to $859.5 \mathrm{MJ} / \mathrm{m}^{2}$, and ultimately get their statistical parameters, the average of 382.97 $\mathrm{MJ} / \mathrm{m}^{2}$, and the standard deviation of $137.33 \mathrm{MJ} / \mathrm{m}^{2}$.

Table 1 Fire load density table

\begin{tabular}{|c|c|c|c|}
\hline \multicolumn{4}{|c|}{ fire load density $\left(M J / m^{2}\right)$} \\
\hline \multirow{2}{*}{ mean value } & \multicolumn{3}{|c|}{ Per centum } \\
\cline { 2 - 4 } & $80 \%$ & $90 \%$ & $95 \%$ \\
\hline 383 & 471 & 499 & 532 \\
\hline
\end{tabular}

The following figure shows the histogram of the fire load density.

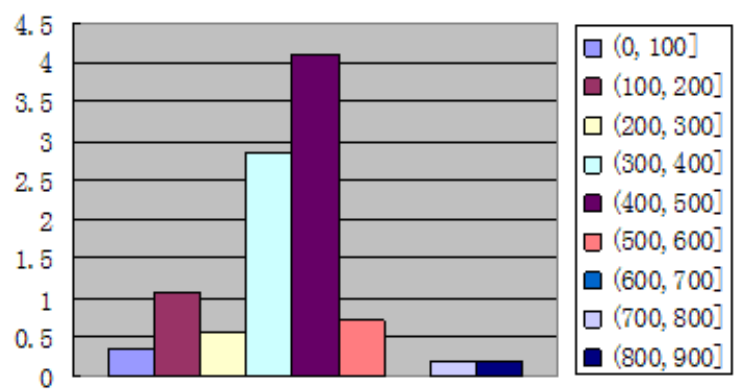

Fig. 3 Histogram of the fire load density

From the histogram figure, the fire load density of exhibition is concentrated in the $300-500 M J / \mathrm{m}^{2}$, the average is also in the data scope.

To fit the data group, normally distributed, logarithmic normal distribution, the distribution of extreme value type I, generalized extreme value, generalized Pareto distribution were processed [4]. After the calculation, the data distribution is not refused to obey the extreme value type I distribution, and its distribution can be expressed by the formula:

$$
F(x)=\exp \{-\exp [-0.0093(x-321.17)]\}
$$

The maximum value probability distribution during the period of design basis distribution as follows:

$$
F_{i T}=\exp \{-\exp [-0.0093(x-489.19)]\}
$$

Statistical parameters of $F_{T}(x)$ for the design basis period of T:

$$
\begin{aligned}
& \mu_{L T}=550.99 \\
& \sigma_{L T}=137.22
\end{aligned}
$$


According to the group preliminary work [3], there carried out calculation of fire load standard value to the exhibition building, the standard value as follows:

$$
u_{k}=876.21 \mathrm{MJ} / \mathrm{m}^{2}
$$

\section{Summary}

1) The exhibition economy development rapidly, fire hazard is great. In particularly, the exhibition with naked flame operations should be paid more attention. This exhibition has its own characteristics as a tourist exhibition, the value would not be applied to clothing exhibition of Beijing Agricultural Exhibition Hall, International Convention and Exhibition Center - this class exhibition tends to clothing stores, but because of its short-term behavior, smaller stock, fire load should be smaller than the clothing stores in shopping mall.

2) The movable fire load statistics data is proposed to apply on these types such as business promotion, industrial products exhibition, job fair, and is designed to provide support for fire performance-based design. For other types of buildings are not suggested to use this data without any survey and validation.

3) The exhibition building is almost no fixed fire load, so the fire load values can be directly applied to the fire temperature estimation, and on the basis to progress fire design.

\section{Acknowledgements}

This work was supported by the Projects "Typical building fire load survey and statistical analysis” of China Academy of Building Research Institute (N0. 20120111330730062).

\section{References}

[1] Jinping Wang, Hongtao Liu. Calorific value of commonly used building materials and furniture and fire load density determination [J].Building Science. Vol. 25-5 (2009) :19-21

[2] Yingqing $\mathrm{Li}$, DaoZhen $\mathrm{Ma}$, Jian $\mathrm{Xu}$, Structural fire design calculations and construction processing [M] Beijing: China Building Industry Press, 1991.

[3] Jinping Wang, Jiang Zhu, Beijing residential activity room fire load survey analysis and the standard values determination [J].Building Science. Vol. 26-1 (2010):24-29

[4] Jinping Wang. The theoretical study of active fire load determination in construction[C], proceedings of 2009 international symposium of fire science and fire-protection engineering. 2009(11)

[5] Jinping Wang. The discussion on fire load maximum of building [J].Applied Mechanics and Materials Vols. 166-169 (2012):2709-2712 